\title{
INVESTIGATION OF THERMAL CONDUCTIVITY OF LUFFA AND LUFFA-COIR REINFORCED EPOXY COMPOSITES
}

\author{
K. Anbukarasi ${ }^{* 1}{ }^{凶}$, S. Imran Hussain ${ }^{2}$, S. Kalaiselvam ${ }^{2}$ \\ ${ }^{* 1}$ Department of Mechanical Engineering, ThanthaiPeriyar Government institute of Technology, \\ Vellore 632 002, India \\ 2 Department of Applied Science and Technology, AC Tech Campus, Anna University, \\ Chennai 600 025, India
}

DOI: https://doi.org/10.29121/granthaalayah.v8.i12.2020.2534

Article Type: Research Article

Article Citation: K. Anbukarasi, S. Imran Hussain, S. and Kalaiselvam. (2020). INVESTIGATION OF THERMAL CONDUCTIVITY OF LUFFA AND LUFFA-COIR REINFORCED EPOXY COMPOSITES. International Journal of Research GRANTHAALAYAH, 8(12), 69-79. https://doi.org/10.29121/granthaa layah.v8.i12.2020.2534

Received Date: 25 November 2020

Accepted Date: 26 December 2020

Keywords:

Natural Fibre

Epoxy

Hybrid

Thermal Conductivity

Theoretical Model

Thermal Stability

\section{ABSTRACT}

Thermal behavior of luffa and coir reinforced epoxy composites have been evaluated for a constant total fiber volume fraction $0.4 \mathrm{Vf}$ by varying the ratio of luffa and coir fiber. Thermal conductivity of luffa-epoxy and luffa-coir reinforced epoxy composite was studied experimentally and analytically in terms of fiber size and fiber volume. Thermal conductivity of composites was investigated experimentally by a guarded heat flow meter method. The experimental results at different volume fraction were compared with three theoretical models. The composite $\mathrm{C}$ has the lowest thermal conductivity of $0.206 \mathrm{~W} / \mathrm{mk}$ with $0.81 \%$ of voids. The experimental values of thermal conductivity of hybrid composites are the good correlation with the Maxwell and Maxwell-Eucken models. As in a case of $0.4 \mathrm{Vf}$ of luffa-epoxy composites these values are closer to the rule of mixture models. The thermal stability of the composites was investigated by thermogravimetric analysis. This result reveals that the hybridization of luffa and coir with epoxy allows a significantly improved insulation ability of the composites.

\section{INTRODUCTION}

The eco-friendly and efficient natural fibers have been applied as a potential alternative for traditional glass fibre and other synthetic polymer fibers for diverse engineering applications. Their significant advantages compared with the conventional inorganic manmade fibers enhance their commercial and research potentials. Natural fibres are abundantly available renewable and biodegradable resource, so that their cost is relatively low. Besides, natural fibers are flexible for processing due to their less susceptible to health hazards during the manufacturing. Natural cellulosic fibers reinforced polymer composites offers a number of advantages over conventional materials such as considerable toughness, flexibility, easy processing, biodegradability, recyclability and eco-friendliness etc. the Porous and lightweight cellulose fiber reinforced composite a suitable applicant as the thermal protection shield in building and interior of vehicles[1],[2],[3]. Thermoset polymer epoxy makes an excellent matrix

(C) 2020 The Author(s). This is an open access article distributed under the terms of the Creative Commons Attribution License, which permits unrestricted use, distribution, and reproduction in any medium, provided the original author and source are credited. 
material[2],[3],[4],[5] because of their excellent adhesive property, versatility, good handling characteristics, low shrinkage, flame resistant, good chemical resistance, good mechanical properties. Untreated natural fiber does not have effective interface bond with the matrix, due to their hydrophilic behaviour. The presence of hemicellulose in the natural fiber is a main factor for higher moisture absorption of the composite.

Silane, MAPP and alkali treated luffa fiber increases the mechanical properties such as tensile, compressive, flexural, impact strength and water absorption behaviour of luffa fiber composites and compared with untreated fiber due to the removal of hemicellulose, lignin from fiber through fiber treatment. Besides the removal of lignin will increase the onset temperature (thermal stability) of the composite. Since, the compatibility and interface adhesion between the matrix (polypropylene, epoxy etc.) and treated fiber[6],[7],[8]. Similarly, the alkali treated coir fiber reinforced epoxy composites [1] has higher thermal stability than untreated coir fiber composites. Generally, addition of lignocellulosic fiber in high-density polymer matrix like polypropylene, epoxy, polyester etc. reduces the thermal stability of composites compared to the neat polymer matrix, due to an earlier decomposition of hemicellulose in the fiber. Mercerization and silane treatment of fiber on TTC of unidirectional abaca fiber reinforced epoxy composites [9] build the pass way for heat flow in composites was enhanced due to the fiber and resin interface adhesion. But in heavy mercerization, interfaces condition plays a minor role in the enhancement of TTC compared with lumen disappearing. Chemical treatment of fiber allows a better contact between the fiber and matrix; besides, it allows a significant increase of both thermal conductivity and density of hybrid composites[10].

Thermal conductivity is a very important property for the applications of fiber reinforced composites in the area of building construction, automobile interior, and electronic devices.

Various theoretical approaches are used to predict the thermal conductivity of a composite material so that the heat flow in an anisotropic composite material in any direction can be estimated. Comparing the result of the study with an existing theoretical model [11] of pine bark reinforced epoxy polymer composites with and without aluminium, copper and industrial waste like cement bypass dust filler content. It could be concluded that the experimental value of thermal conductivity of pine bark fiber reinforced epoxy composites made in longitudinal and through the thickness direction are in good agreement with the theoretical model. The thermal conductivity of composites according to bagasse fiber content and fiber treatment, the good correlation was exit between the predicted value of thermal behaviour of bagasse fiber reinforced cement composites and Maxwell- Eucken modeling [12]. Also, the result confirmed that the thermal conductivity is inversely proportional to the void in the composites. The thermal conductivity of the composites decreases as fiber volume increases this may be the presence of lower thermal conductivity fiber in resin [12],[13]

In case of transverse thermal conductivity, (TTC) of bamboo fiber reinforced epoxy [14] composites increase with an increasing in fiber loading this is contradicted to the result of abaca fiber/epoxy composites. [15] They investigated the thermal conductivity of jute/cotton, sisal/cotton and ramie/ cotton hybrid fabric reinforced unsaturated polyester composites. Thermal conductivity was measured both parallel and perpendicular to the plane of the fabrics. The results show that higher values were obtained parallel to the plane of the fibers.

In this work, an attempt is made to utilize the natural available network structure of mat shape luffa fiber. In order to get pores free composites, cellulosic fiber coir is used in pulverized form with luffa to occupy pore in the mat. Thermal conductivity of alkali treated luffa at different dimensions like single fiber and mat fiber reinforced epoxy composites at different fibre volume fractions such as $0.3,0.4$, and 0.5 are predicted experimentally and theoretically. Similarly, hybrid composite is prepared at different ratio of luffa and coir at constant fiber volume $\left(0.4 V_{f}\right)$. The report presents the thermal stability, thermal conductivity, porous volume and density of all the composites. FESEM analyses were carried out to study the interface bonding, pores and voids present in the composites.

\section{MATERIALS AND METHODS}

\subsection{MATERIALS}

The low temperature curing epoxy resin Araldite LY 556 (Bisphenol-A-Diglycidyl-Ether) and the corresponding hardener (HY 951) are mixed in a ratio of 10:1 by weight as recommended. These were supplied by M/s. Sakthi fibre glass, Chennai. Epoxy is chosen, since it is most commonly used polymer and also its insulating nature (low value of thermal conductivity, about $0.363 \mathrm{~W} / \mathrm{m}-\mathrm{K}$ ). Physical properties of epoxy composite are shown in Table 1. 
K. Anbukarasi, S. Imran Hussain, S. and Kalaiselvam.

Table 1: Physical properties of epoxy

\begin{tabular}{|l|c|}
\hline \multicolumn{2}{|l|}{ Araldite ${ }^{\circledR} \mathrm{LY} 556$ (data provided by manufacturer) } \\
\hline Aspect (visual) & clear, pale yellow liquid \\
\hline Viscosity at $25^{\circ} \mathrm{C}$ (ISO 9371B) [mPa s] & $10000-12000$ \\
\hline Density at $25^{\circ} \mathrm{C}(\mathrm{ISO} 1675)[\mathrm{g} / \mathrm{cm} 3]$ & $1.15-1.20$ \\
\hline
\end{tabular}

Cylindrical shape luffa fibres were extracted from fibrous strands. The collected dried luffa fibres were kept under the sunlight over a period of a week. luffa fiber is initially washed with water to remove dirt and other impurities. The cleaned luffa fibers were then immersed in a $2 \% \mathrm{NaOH}$ solution and rinsed for 2 hours at room temperature.The fiber is taken out, neutralized the solution with dilute acetic acid solution ( $2 \mathrm{~N}$ ), and finally luffa fibers washed with distilled water to remove the excess of solution sticking to them. The Luffa fibers were then dried under sunlight for 2 to 3 weeks. The alkalization treatment removes impurities and increases the fiber surface adhesion behavour with the resin. Hence decreases of voids in an interface. Besides, penetration and storage of water through the void was restricted. Physical properties of luffa fibers are shown in table 2.

Table 2: physical properties of luffa fibers [16]

\begin{tabular}{|c|c|}
\hline \multicolumn{2}{|c|}{ Some physical aspects of Luffa fiber } \\
\hline Density untreated(g/cc) & $0.92 \pm 0.10$ \\
\hline Density treated with $\mathrm{NaOH}(\mathrm{g} / \mathrm{cc})$ & 0.83 \\
\hline Diameter $(\mu \mathrm{m})$ & $270 \pm 20$ \\
\hline Thermal conductivity $(23 \mathrm{C})$ untreated $(\mathrm{W} / \mathrm{mK})$ & 0.015 \\
\hline Thermal conductivity $(23 \mathrm{C})$ treated $(\mathrm{W} / \mathrm{mK})$ & 0.023 \\
\hline Aspect ratio $(\mathrm{l} / \mathrm{d})$ & $340 \pm 5$ \\
\hline
\end{tabular}

Since coir is also lignocellulosic fibers the treatment procedure is similar to that of luffa fibers. This treated coir was then pulverized in a mill into fine particles and filtered through a sieve of pores $300 \mu \mathrm{m}$, these particles may be spherical, elliptical, tetragonal or other shapes. But it has assumed as approximately equal [17]. Normally particles increase the stiffness of the composites to a certain limit were used for making composites. Physical properties of coir fiber are shown in table 3.

Table 3: properties of coir fiber [18]

\begin{tabular}{|c|c|}
\hline Property & Value \\
\hline Density (g/cc) & 1.2 \\
\hline Lignin & $42 \%$ \\
\hline Cellulose & $37 \%$ \\
\hline Thermal conductivity (W/m-K) & 0.0518 \\
\hline
\end{tabular}

\subsection{PROCESSING METHODS}

The mould surface was allowed to dry cleaning with a thinner solution. Dried mould surface was coated with an anti-adhesive agent. The mirror polished mould plate was machined to the size of $300 \times 300 \times 3 \mathrm{~mm}$. Weighed quantity of mat fibres were arranged by hand in the mould before adding resin. The coir powder was mixed with weighed amount of epoxy resin in a bowl, stirred thoroughly by mechanical stirrer to disperse the fibre in the matrix, and then poured into the mould slowly over the mat fibre to avoid air trapping, then the mould is closed and compressed. The mould remains closed for twenty-four hours during which the resin gets cured. The composite plate was taken from the mould and allowed to be post cured in the air for 24 hours.

The alkali treated luffa fibre was prepared at different dimensions like single fibre (chopped fiber), and mat fibre, then they were reinforced in epoxy resin at different fibre volume fractions of $0.3,0.4$, and 0.5 . in order to improve the mechanical and thermal properties of luffa-epoxy composites coir fiber were added with that composition. Luffa and coir hybrid composites were prepared for a constant total fiber volume of 0.4 by varying the ratio of luffa and coir fiber. The details of twelve different samples were fabricated are labeled in table 4 .

International Journal of Research -GRANTHAALAYAH 


\subsection{CHARACTERIZATION}

\subsubsection{THERMAL ANALYSIS}

Study of thermal characteristics of luffa/epoxy and luffa/coir epoxy composites provide the information about thermal stability and thermal conductivity of composites. The guarded flow heat meter is used to experimentally investigate the thermal conductivity of the composites. This method is in conformance to the ASTM E 1530 standards. The thermal conductivity test in this work was conducted on Unitherm 2022 at room temperature.

Table 4: Combination of different fiber volume fraction of the composites

\begin{tabular}{|c|c|c|c|c|}
\hline Sl. No & LABEL & $\begin{array}{c}\text { LUFFA FIBRE } \\
\text { (\% By Vol.) }\end{array}$ & $\begin{array}{c}\text { COIR } \\
\text { (\% By Vol.) }\end{array}$ & $\begin{array}{c}\text { EPOXY } \\
\text { (\% By Vol.) }\end{array}$ \\
\hline 1 & TC30 & 30 (in chopped form) & 0 & 70 \\
\hline 2 & TC40 & 40 (in chopped form) & 0 & 60 \\
\hline 3 & TC50 & 50 (in chopped form) & 0 & 50 \\
\hline 4 & TM30 & 30 (in mat form) & 0 & 70 \\
\hline 5 & TM40 & 40 (in mat form) & 0 & 60 \\
\hline 6 & TM50 & 50 (in mat form) & 0 & 50 \\
\hline 7 & A & 0 & 0 & 100 \\
\hline 8 & B & 0 & 20 & 80 \\
\hline 9 & C & 20 & 20 & 60 \\
\hline 10 & D & 25 & 15 & 60 \\
\hline 11 & E & 30 & 10 & 60 \\
\hline 12 & F & 35 & 5 & 60 \\
\hline
\end{tabular}

Thermogravimetric analysis (TGA) and differential thermal analysis (DTA) were carried out by using thermal analysis instrument Netzsch STA 409 PL Luxx, at a flow rate of $20 \mathrm{ml} / \mathrm{min}$ and at heat rate of $10 \mathrm{~K} / \mathrm{min}$ under nitrogen atmosphere. $10 \mathrm{mg}$ of each sample was placed on a platinum pan and heated from $30^{\circ} \mathrm{C}$ to $600^{\circ} \mathrm{C}$. The onset temperature of degradation and residue mass were obtained from the TGA curve.

\subsubsection{FESEM analysis}

The fractured surfaces of the composite specimens were examined by Field Emission Scanning Electron Microscope (Zeiss Supra 55) with an accelerator voltage 3KV. The dispersion of fibres in matrix and interface bonding between the fibre and matrix of the composites were examined through the SEM images. The fractured specimen surfaces coated with gold vanadium to avoid charging.

\section{RESULTS AND DISCUSSION}

\subsection{DENSITY AND VOID FRACTION}

In many applications, polymer composites are found to replace conventional metals primarily for their low densities. The density of a composite depends on the proportion of the reinforcement and matrix materials. The density of luffa fiber reinforced epoxy composites is calculated theoretically by using Eq. (1) [3].

$$
\rho_{c t}=\frac{1}{\left(\frac{W_{f}}{\rho_{f}}\right)+\left(\frac{W_{m}}{\rho_{m}}\right)}
$$


$\mathrm{W}_{\mathrm{f}}, \rho_{f}$ and $\mathrm{W}_{\mathrm{m}}, \rho_{m}$ represents the weight fraction, the density of fiber and matrix of the composite respectively. The theoretical density of hybrid composites is calculated by using the modified form of equation 1 can be written as

$$
\rho_{c t}=\frac{1}{\left(\frac{W_{f 1}}{\rho_{f 2}}\right)+\left(\frac{W_{f 2}}{\rho_{f 2}}\right)+\left(\frac{W_{m}}{\rho_{m}}\right)}
$$

Where the suffix f1 and f2 are represent luffa and coir fiber respectively. Whereas the actual density $\left(\rho_{c e}\right)$ of the composites can be experimentally predicted by using the water immersion technique (Archimedes methods) $[10,19]$. Beside that the volume fraction of voids $V_{v}$ presented in the composites is calculated by using the equation $3[3]$.

$$
V_{V}=\frac{\rho_{c t}-\rho_{c e}}{\rho_{c t}}
$$

Theoretical and measured densities of luffa-epoxy and luffa/coir-epoxy hybrid composites are compared and along with the corresponding volume fraction of voids are presented in Table 5. From this comparison, it can be observed that there is a difference between the measured and the theoretical values of density due to the presence of voids and pores in the composites. These voids significantly affect the mechanical properties of composites. [12],[19] Higher void contents lead to lower the mechanical strength, good susceptibility to water absorption. Hence, the information of void content is desirable for understanding of the quality of the composite.

It has been observed that the density and void fraction of luffa-epoxy composites decrease with the increase of fiber content irrespective of luffa fiber dimension [20]. Besides, the density values of luffa-epoxy composites have increased with the addition of pulverized coir fiber. It was also observed that voids percentage increases as decreases of coir fiber due to incomplete filling of pores in the mat, this is evidently proved by the SEM images. It is further observed that with the incorporation of coir particulate, the void fractions in these composites increases up to $0.1 \mathrm{~V}_{\mathrm{f}}$ of coir, beyond that it is starting to decrease. Since, the presence of voids in mat shape luffa fiber occupied by coir particulate content.

Table 5: Theoretical and measured densities along with the void fractions of the luffa-epoxy composites and luffa/coir epoxy composites.

\begin{tabular}{|c|c|c|c|c|}
\hline Sl. No & Label & Actual density $\left(\mathrm{g} / \mathrm{cm}^{3}\right)$ & Theoretical density $\left(\mathrm{g} / \mathrm{cm}^{3}\right)$ & Void in $\%$ \\
\hline 1 & TC30 & 1.059 & 1.076 & 1.57 \\
\hline 2 & TC40 & 1.028 & 1.041 & 1.25 \\
\hline 3 & TC50 & 1.001 & 1.006 & 0.50 \\
\hline 4 & TM30 & 1.057 & 1.076 & 1.75 \\
\hline 5 & TM40 & 1.026 & 1.041 & 1.44 \\
\hline 6 & TM50 & 1.003 & 1.006 & 0.30 \\
\hline 7 & A & 1.175 & 1.180 & 0.42 \\
\hline 8 & B & 1.160 & 1.184 & 1.99 \\
\hline 9 & C & 1.1 & 1.109 & 0.81 \\
\hline 10 & D & 1.085 & 1.097 & 1.12 \\
\hline 11 & E & 1.058 & 1.077 & 1.79 \\
\hline 12 & F & 1.046 & 1.060 & 1.28 \\
\hline
\end{tabular}

\subsection{THERMAL STABILITY OF COMPOSITES}

Initially, mat and chopped type of luffa reinforced epoxy composite specimens are analyzed. Generally thermal stability of the composite has been measured in term of onset temperature and mass losses. The decomposition of 
cellulose and hemicelluloses of fibre in the composites took at onset temperature. The composites are thermally stable and can be used up to the onset temperature. Since a mass loss begins above this temperature due to the decomposition of composites [1],[6]. From thermogravimetric analysis result, it has been observed that the onset temperatures for (chopped and mat) luffa-epoxy composites and hybrid composites varied from $341{ }^{\circ} \mathrm{C}$ to $387.2 \circ \mathrm{C}$ and $268^{\circ} \mathrm{C}$ to $300^{\circ} \mathrm{C}$ respectively. From the previous study [6] it was found that chopped (single) fiber reinforced composites has better thermal stability than mat fiber reinforced composites. Hybrid composites have lower onset temperature and mass losses compared with luffa-epoxy composites. As an increase of volume of coir in hybrid composites, their thermal stability has improved as shown in table 6. Due to the density of composites has improved as increases of coir in hybrid composites.

Table 6: Thermo-gravimetric analysis results of various composites

\begin{tabular}{|c|c|c|c|c|}
\hline Sl NO & Sample label & Onset Temperature in Co & Mass in \% at onset temperature & Residue mass at $600^{\circ} \mathrm{C}$ \\
\hline 1 & TC30 & 355.2 & 71.0 & 17.23 \\
\hline 2 & TC40 & 369 & 71.84 & 16.28 \\
\hline 3 & TC50 & 387.2 & 52.83 & 16.41 \\
\hline 4 & TM30 & 371.1 & 58.3 & 13.74 \\
\hline 5 & TM40 & 351.3 & 74.43 & 20.20 \\
\hline 6 & TM50 & 341.4 & 80.72 & 23.98 \\
\hline 7 & A & 339 & 91.11 & 10.68 \\
\hline 8 & B & 328 & 87.34 & 14.37 \\
\hline 9 & C & 268 & 91.80 & 18.44 \\
\hline 10 & D & 270 & 92.75 & 15.35 \\
\hline 11 & E & 300 & 89.95 & 25.24 \\
\hline 12 & F & 292 & 92.96 & \\
\hline
\end{tabular}

\subsection{THERMAL CONDUCTIVITY OF COMPOSITES}

The thermal conductivity behaviour of different composites can be explained using thermal conductivity values of fibers. The conductivity of the epoxy composites decreases with the addition of luffa fiber by $35 \%$ and $39.3 \%$ for $0.4 \mathrm{~V}_{\mathrm{f}}$ of chopped and mat fiber reinforced composites respectively. Further with the addition of $0.2 \mathrm{~V}_{\mathrm{f}}$ of coir in luffaepoxy composites, the thermal conductivity decreases by $43.2 \%$ for samples $\mathrm{C}$. The measured thermal conductivity of composites was compared with rule of mixture parallel model, Maxwell model and Maxwell-Eucken model [12],[19]. The expressions for these three models are

Parallel model: $\quad k=V_{f}+\left(1-V_{f}\right) k_{m}$

Maxwell model: $k=k_{m} \frac{k_{f}+2 k_{m}+2 V_{f}\left(k_{f}-k_{m}\right)}{k_{f}+2 k_{m}-V_{f}\left(k_{f}-k_{m}\right)}$

Maxwell - Eucken: $k=\frac{k_{m} V_{m}+k_{f} V_{f}\left(\frac{3 k_{m}}{2 k_{m}+k_{f}}\right)}{V_{m}+V_{f}\left(\frac{3 k_{m}}{2 k_{m}+k_{f}}\right)}$

Assumed as $\mathrm{V}_{\mathrm{m}}+\mathrm{V}_{\mathrm{f}}=1$ 
Where $\mathrm{V}_{\mathrm{m}}$ and $\mathrm{Vf}$ are volume fraction of matrix and fiber in the composites respectively, similarly $\mathrm{k}, \mathrm{k}_{\mathrm{m}}$ and $\mathrm{k}_{\mathrm{f}}$ are thermal conductivity of composite, matrix and fiber respectively. Fig. 1 and 2 show the prepared samples for thermal conductivity test.
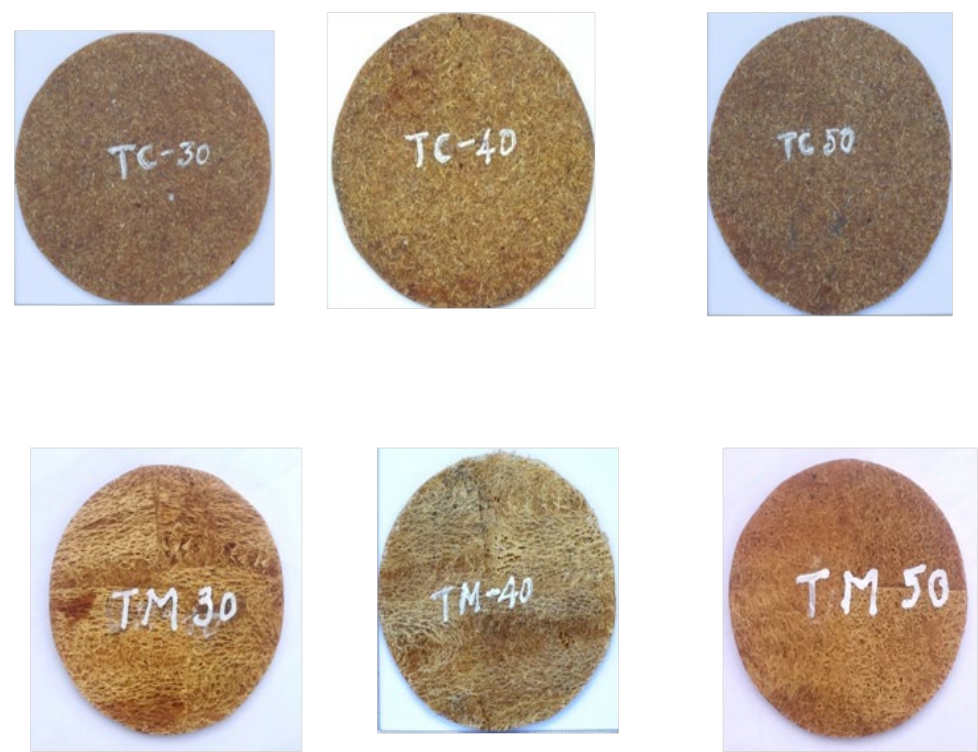

Figure 1: Treated chopped and mat composite Samples for thermal conductivity test

From the results, it is found that the thermal conductivity of sample A (table 7.) is the highest followed by the combination of resin and $0.2 \mathrm{~V}_{\mathrm{f}}$ of coir powder. The lowest thermal conductivity is that of the sample $\mathrm{C}$ which consists of $0.2 \mathrm{~V}_{\mathrm{f}}$ of coir and Luffa fibers. It is also observed that the thermal conductivity of chopped luffa fiber reinforced composites has relatively high value than that of the mat fiber reinforced composites. Since, chopped fiber get good dispersion with epoxy, further their densities little bit higher. Fig.3 and 4. Show the effect of fiber volume on thermal conductivity of the composites, as volume fraction of the fibers increases the thermal conductivity of the composites decreases due to the reinforcement of lower thermal conductivity fibers. From the fig.3, it can also be observed that there is a slight difference exit between the thermal conductivity of experimentally predicted and theoretical values. This is due to the fact that some assumption has taken for models. In theoretical models, fiber orientation was assumed to be perfect, but in actual practice it may get misplaced due to pouring of coir-matrix mixture over the mat luffa fiber.

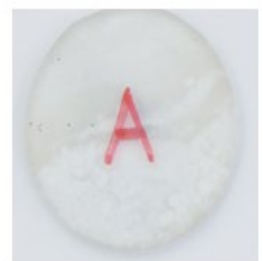

SAMPLE A

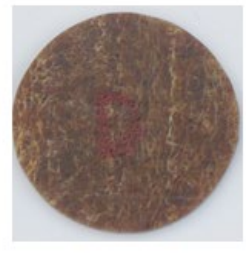

SAMPLE D

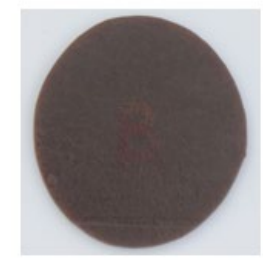

SAMPLE B

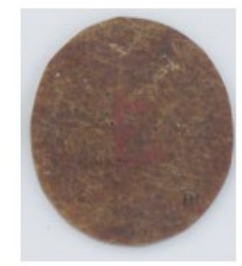

SAMPLE E

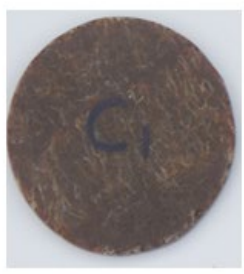

SAMPLE C

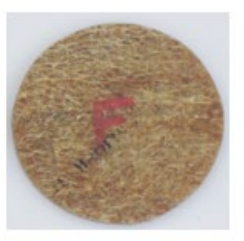

SAMPLE F

Figure 2: a) Epoxy composite, b-f) luffa/coir epoxy hybrid composite samples for thermal conductivity test. 


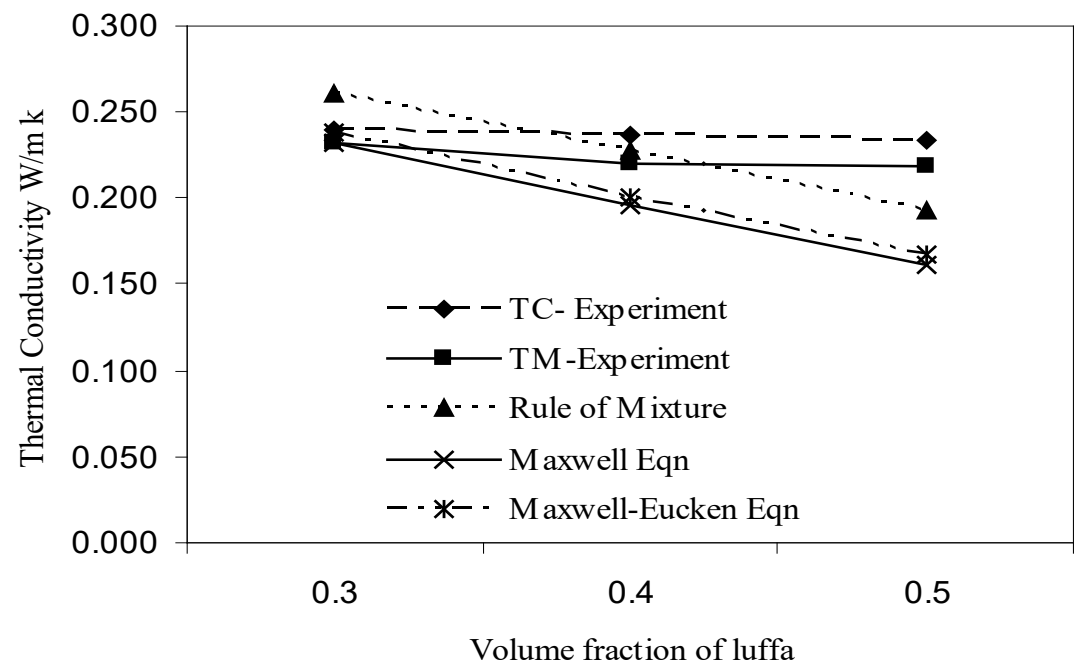

Figure 3: Variation of thermal conductivity of fiber reinforced composite with volume fraction of luffa fibre.

In case of luffa-coir hybrid composites the thermal conductivity is lower when coir and luffa fibers are in equal proportion, fig. 4 shows the thermal conductivity of hybrid composites, from this it has been noted that thermal conductivity increases slightly with increase of coir fibers volume in hybrid composites. The density of composites has been improved with the addition of coir fiber result in increases thermal conductivity due to increases the area of contact zone [21]. Besides, the predicted values of thermal conductivity of these composites have good correlation with Maxwell and Maxwell- Eucken modeling than luffa-epoxy composites. However, the experimental values of thermal conductivity are in good agreement with analytical values at lower fiber volume [22].

Table: 6: Experimental and theoretical thermal conductivity of the luffa-epoxy composites and luffa/coir epoxy composites.

\begin{tabular}{|c|c|l|c|c|c|}
\hline \multirow{2}{*}{ Sl.no } & Sample & \multicolumn{4}{|c|}{ Thermal conductivity $(\mathrm{w} / \mathrm{m} \mathrm{K})$} \\
\cline { 3 - 6 } & & Experimental & ROM-P & Maxwell & Maxwell- Euckan \\
\hline 1 & TC30 & 0.240 & 0.261 & 0.232 & 0.238 \\
\hline 2 & TC40 & 0.236 & 0.227 & 0.196 & 0.201 \\
\hline 3 & TC50 & 0.233 & 0.193 & 0.162 & 0.167 \\
\hline 4 & TM 30 & 0.232 & 0.261 & 0.232 & 0.238 \\
\hline 5 & TM40 & 0.220 & 0.227 & 0.196 & 0.201 \\
\hline 6 & TM50 & 0.219 & 0.193 & 0.162 & 0.167 \\
\hline 7 & A & 0.363 & 0.363 & 0.363 & 0.363 \\
\hline 8 & B & 0.238 & 0.301 & 0.284 & 0.284 \\
\hline 9 & C & 0.206 & 0.233 & 0.211 & 0.208 \\
\hline 10 & D & 0.208 & 0.231 & 0.209 & 0.206 \\
\hline 11 & E & 0.210 & 0.230 & 0.208 & 0.205 \\
\hline 12 & F & 0.215 & 0.228 & 0.206 & 0.203 \\
\hline
\end{tabular}

The effect of luffa fiber volume on voids of the composites has shown in fig.5. As increases of volume fraction of luffa in hybrid composites (constant $V_{f}$ of 0.4 ) the volume of void increases up to $0.3 \mathrm{~V}_{\mathrm{f}}$, because remaining coir fiber is in particle form, they may get dispersed during fabrication it may cause void and pores in the composites. But in case of luffa-epoxy composites as the volume of luffa fiber increases helps to make the void less composite. Since, the availability of luffa fiber is in mat form. 
K. Anbukarasi, S. Imran Hussain, S. and Kalaiselvam.

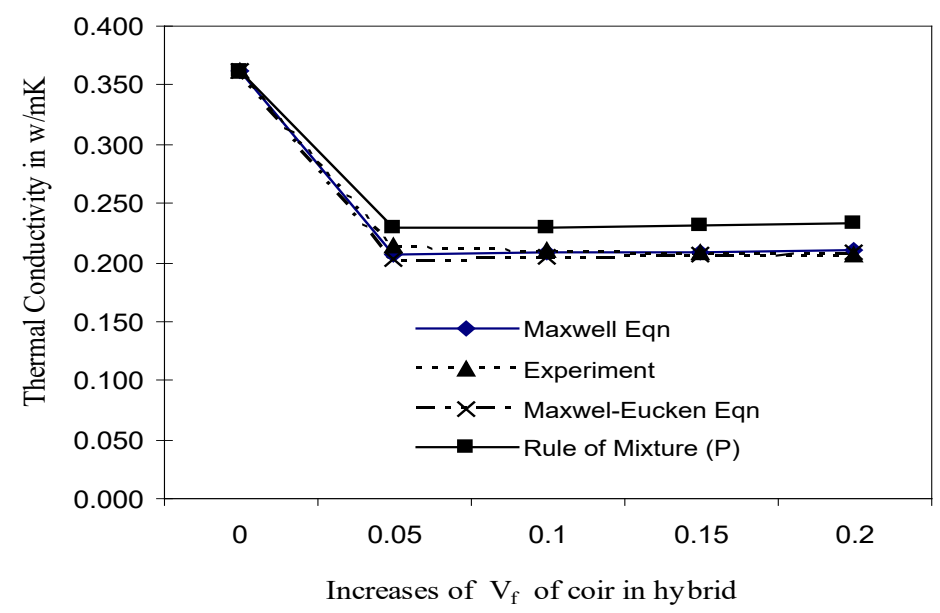

Figure 4: Variation of thermal conductivity of fiber reinforced hybrid composite with volume fraction of coir fibre.

From the fig 6. it can be observed that the presence of voids in the composites does not make much effect in the thermal conductivity of the composites [10].

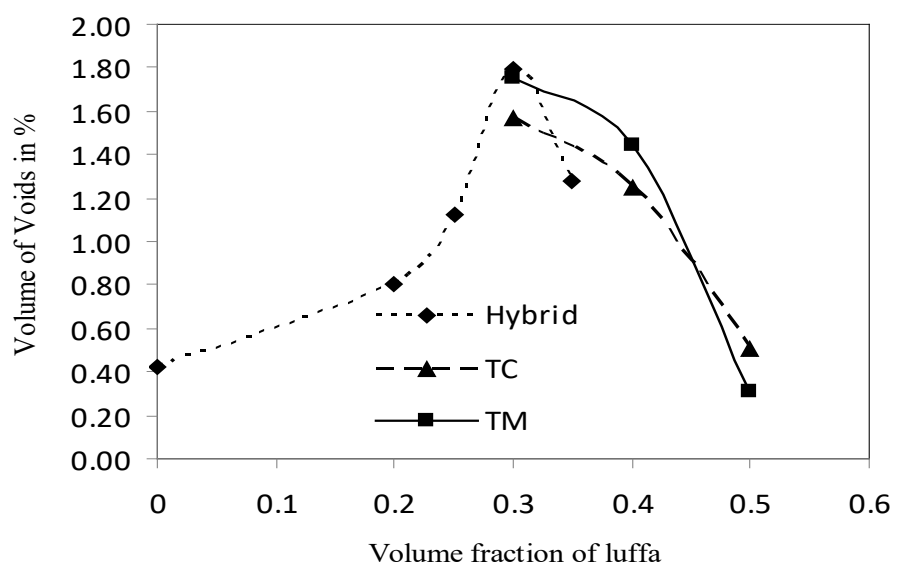

Figure 5: Variation of void present in fiber reinforced composite with volume fraction of luffa fibre.

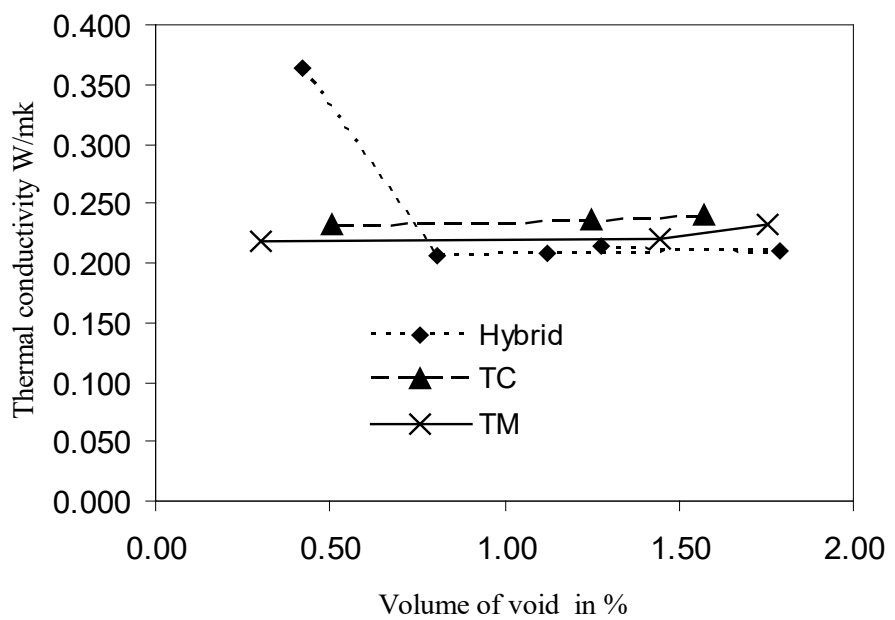

Figure 6: Variation of thermal conductivity of fiber reinforced composite with volume of voids. 


\section{CONCLUSION}

Luffa-epoxy and luffa-coir epoxy composites at the constant total fiber volume fraction of $0.4 \mathrm{~V}_{\mathrm{f}}$ by varying the ratio of luffa and coir fiber volume were fabricated. Thermal stability and thermal conductivity of the composites were predicted experimentally and theoretically.

- Thermal conductivity of epoxy composite has decreased by $39.3 \%$ with the addition of $0.4 \mathrm{Vf}$ of mat fiber.

- The insulating behaviour of the composites has improved by $14 \%$ with the addition of coir particulate in luffa-epoxy composites.

- The density and thermal stability have been improved significantly with adding of coir.

- The result of this work indicate that the luffa and luffa-coir reinforced composites are light in weight, possess good thermal stability and thermal insulating property and moreover economical

- In order to decrease energy consumption, these newly developed composites could be used as the heat transfer reducer in air-conditioned building, automobile interior parts.

\section{SOURCES OF FUNDING}

This research received no specific grant from any funding agency in the public, commercial, or not-for-profit sectors.

\section{CONFLICT OF INTEREST}

The author have declared that no competing interests exist.

\section{ACKNOWLEDGMENT}

None.

\section{REFERENCES}

[1] Sergio N. Monteiro, Veronica Calado, Rube'n Jesus S. et al. Thermogravimetric behavior of natural fibers reinforced polymer composites-An overview. Materials Science \& Engineering A 557, 2012 17-28

[2] Vijay Kumar Thakur, Manju Kumari Thakur. Processing and characterization of natural cellulose fibers/thermoset polymer composites. Carbohydrate Polymers, 109, 2014, 102-117

[3] Santhiyarani Biswas, Amar Patnaik, and Ritesh kaundal. Effect of red mud and copper slag particles on physical and mechanical properties of bamboo-fiber-reinforced epoxy composites. Hindawi publishing corporation Advances in Mechanical Engineering, Vol 2012, Articles ID 141248, 6 pages, doi: $10.1155 / 2012 / 141248$.

[4] Omar Faruka,d, Andrzej K. Bledzkia, Hans-Peter Fink, et al. Biocomposites reinforced with natural fibers: 2000-2010. Progress in Polymer Science, 37, 2012, 1552- 1596.

[5] Valcineide OA. Tanobe, Thais HS. Flores-Sahagun, et al. Sponge Gourd (luffa Cylindrica) Reinforced Polyester composites: Preparation and properties. Defenece science journal, Vol.64, No.3, 2014, 273-280, doi:10.14429/dsj.64.7327.

[6] Anbukarasi, S. Kalaiselvam. Study of effect of fibre volume and dimension on mechanical, thermal,and water absorption behaviour of luffa reinforced epoxy composites. Materials and Design, 66, 2015, 321-330.

[7] Demira H, Atiklera U, Balkosea D, Tihminlıglua F. The effect of fiber surface treatments on the tensile and water sorption properties of polypropylene-luffa fiber composites. Composites: Part A, 37, 2006, 447-456

[8] Azwa ZN, Yousif BF. Characteristics of kenaf fibre/epoxy composites subjected to thermal Degradation. Polymer Degradation and Stability, 98, 2013, 2752-2759

[9] Ke Liu, Hitoshi Takagi, Ryosuke Osugi, Zhimao Yang. Effect of physicochemical structure of natural fiber on transverse thermal conductivity of unidirectional abaca/bamboo fiber composites. Composites: Part A, 43, $2012,1234-1241$ 
[10] Ke Liu, Xiaozhe Zhang, Hitoshi Takagi, et al. Effect of chemical treatments on transverse thermal conductivity of unidirectional abaca fiber/epoxy composite Composites: Part A, 66 2014, 227-236.

[11] Amar Patnaikk, Md Abdulla, Aloa Satapathy, et al. A study on a possible correlation between thermal conductivity and wear resistance of particulate filled polymer composites. Materials and Design, 31, 2010, 837-849.

[12] Cristel Onésippe, Nady Passe-Coutrin, Fernando Toro, et al. Sugarcane bagasse fibres reinforced cement composites: Thermal considerations Composites: Part A, 41, 2010, 549-556

[13] Ramanaiah K, Ratna Prasad AV, Hema Chandra Reddy K. Thermo physical properties of elephant grass fiberreinforced polyester composites. Materials Letters, 89, 2012, 156-158

[14] Maries Idicula, Abderrahim Boudenne, Umadevi L et al. Thermophysical properties of natural fibre reinforced polyester composites. Composites Science and Technology, 66, 2006, 2719-2725.

[15] Alsinaa OLS, De Carvalhob LH, Ramos Filhob FG et al. Thermal properties of hybrid lignocellulosic fabricreinforced polyester matrix composites. Polymer Testing, 24, 2005 81-85.

[16] Sudhir Kumar Saw, Raghwendra Purwar, Sourabh Nandy, et al. Fabrication, Characterization, and Evaluation of Luffa Cylindrica Fiber Reinforced Epoxy Composites. Bioresources.com. 2013

[17] Verma1 D, Gope PC, Shandilya1 A, et al. Coir Fibre Reinforcement and Application in Polymer Composites: A Review. J. Mater. Environ. Sci. 4 (2), 2013, 263-276.

[18] Journal of brazilian society for natural fibers www.scielo.br/scielo.php?pid=51678-58782006000100005.

[19] Johan banjare, yagya kumar sahu, alok agrawal, et al. Physical and thermal characterization of red mud reinforced epoxy composites: an experimental investigation. Procedia material science, 5, 2014, 755-763.

[20] Ramanaiah K, Ratna Prasad AV, Hema Chandra Reddy K. Thermal and mechanical properties of waste grass broom fiber-reinforced polyester composites. Materials and Design 40, 2012, 103-108.

[21] Giedrius Balčiūnas, Sigitas Vejelis, Saulius Vaitkus, et al. Physical Properties and Structure of Composite Made by Using Hemp Hurds and Different Binding, Materials Procedia Engineering, 57, 2013, 159 - 166

[22] Amar Patnaik, Md Abdulla, Alok Satapathy, et al. A study on a possible correlation between thermal conductivity and wear resistance of particulate filled polymer composites. Materials and Design, 31, 2010, 837-849. 